\title{
Low STMN1 is associated with better prognosis in Asian patients with esophageal cancers: a meta-analysis
}

\author{
Shasha Cao \\ Anyang Cancer Hospital \\ Wei Zhang \\ The Third Affiliated Hospital of Zhengzhou University \\ Peihong Shen \\ Zhengzhou University Affiliated Tumor Hospital \\ Ruiping Xu ( $\sim$ aywy05@126.com) \\ Anyang Cancer Hospital
}

\section{Research article}

Keywords: STMN1, esophageal cancer, survival, biomarker, meta-analysis

Posted Date: July 9th, 2019

DOI: https://doi.org/10.21203/rs.2.11117/v1

License: @ (i) This work is licensed under a Creative Commons Attribution 4.0 International License. Read Full License

Version of Record: A version of this preprint was published at Journal of Gastroenterology and Hepatology on April 26th, 2020. See the published version at https://doi.org/10.1111/jgh.15062. 


\section{Abstract}

Background The role of STMN1 in the development and progression of esophageal carcinoma is not yet determined. The present study aimed to systematically evaluate the correlation between STMN1 and prognosis of patients with esophageal carcinoma. Methods Electronic databases including PubMed, Embase, the Cochrane library, and Chinese Biomedical Literature Database (CBM) were searched to identify studies evaluating the impact of STMN1 on the survival of esophageal cancer patients, without the language limitation. Two investigators screened the literature according to the inclusion and exclusion criteria and evaluated the quality of the included studies. The combined analysis was performed using RevMan5.3 software. Results A total of 8 studies, involving 1240 esophageal carcinoma patients, were included in this retrospective design. Meta-analysis showed that esophageal carcinoma patients with low STMN1 had a superior overall survival (OS) and disease-free survival (DFS) than those with high expression of STMN1. Compared to the high expression of STMN1, the 5-year survival rate was significantly higher in patients with low level of STMN1. Patients with high STMN1 expression had a higher risk of experiencing clinical grade III-IV disease, lymph node metastasis, and tumor invasion than those with low STMN1. Conclusion STMN1 is an indicator for the prognosis of esophageal carcinoma patients.

\section{Background}

Esophageal cancer is a common malignant tumor of the digestive system, with high morbidity and mortality that severely threatens the health and the quality of life of patients [ 1]. Esophageal cancer includes esophageal squamous cell carcinoma and esophageal adenocarcinoma; the esophageal squamous cell carcinoma is the most common type in esophageal cancers [1]. Invasion and metastasis are the primary causes of esophageal cancer-related deaths and the key factors threatening the survival of these patients [2]. The transformation is a complicated process and controlled by multiple genes, involving several steps and stages [1].

The microtubule destabilizing phosphoproteins are kinetics of microtubules. These are expressed in a variety of cancer tissues and participate in cell proliferation, cell movement, microtubule dynamics regulation, and cycle regulation [ 3]. STMN1, also known as stathmin 1, is encoded by the STMN1 gene localized on human chromosome 1p36.1 [3, 4]. The expression of the STMN1 protein can be altered during mitosis and cell division [3]. Thus, it might play a role in the invasion and metastasis of tumors owing to its role in the cellular movement. In recent years, STMN1 has been reported to promote the metastasis of bladder cancer, gastric cancer, colorectal cancer, breast cancer, nasopharyngeal carcinoma, and sarcoma [ 5, 6]. However, the impact of STMN1 on the prognosis of esophageal cancer is yet under investigation, albeit the prognosis of esophageal cancer is closely related to the degree of tumor differentiation, staging, and complication [1]. Poor prognosis of esophageal cancer is often associated with invasiveness and metastasis. Therefore, biological indicators related to the development and prognosis of esophageal cancer are a prerequisite. Nevertheless, STMN1 has been shown to play a key role in the prognosis of esophageal cancer, deeming it as a cancer-associated gene [ 7-10].

To date, no meta-analysis has evaluated the specific correlation between STMN1 and prognosis of esophageal cancer patients. Thus, the present study used evidence-based literature to statistically analyze the correlation between STMN1 expression and survival and prognosis in esophageal cancer patients and to explore the correlation between STMN1 and the clinicopathological parameters of esophageal cancer in order to provide the prognostic evidence for the management of the disease.

\section{Methods}

\section{Literature search}

Electronic databases including PubMed, Embase, the Cochrane library, and Chinese Biomedical Literature Database (CBM) were searched to identify the potentially eligible without language limitation. The retrieval period was from the inception of the database to September 2018. Studies evaluating the impact of STMN1 on the survival of esophageal cancer patients were collected. The search terms were as follows and were used in various combinations: STMN1, stathmin 1, esophageal carcinoma, esophageal cancer, esophageal squamous cell carcinoma, esophageal adenocarcinoma, survival, prognosis, and metastasis.

\section{Inclusion and exclusion criteria}


Inclusion criteria

(1) Clinical studies investigating the correlation between STMN1 expression and prognosis and the clinicopathological characteristics of esophageal cancer patients; (2) The diagnosis of esophageal cancer was based on the clinical and pathological evidence. Radiotherapy or chemotherapy was not administered before evaluating the expression of STMN1; (3) Studies had a clear definition of STMN1 expression. The STMN1 expression was detected by immunohistochemistry (IHC) staining or Western blot; (4) Statistical methods were applied appropriately, and the data quality was reliable. The hazard ratio (HR) value and the related $95 \%$ confidence interval $(\mathrm{Cl})$ for survival were obtained. In the case of duplicate publication, the study with the largest sample size was included.

Exclusion criteria

(1) STMN1 detection method and the positive judgment criteria were not mentioned; (2) Duplicate reports or studies that were unusable, such as similar data and poor-quality data; (3) Summary, review, conference summary, and case report articles; (4) The study model was not human.

\section{Data extraction and literature quality evaluation}

The relevant potential studies were retrieved from the above search. Then, the titles and abstracts of the articles were reviewed, and those that failed to meet the inclusion criteria were excluded. The full-text was reviewed if the literature consisting of titles and abstracts was difficult to judge. The process of study selection was completed by two researchers, independently. In the event of discrepancies in the conclusions, a third researcher was involved.

The quality of the selected studies was evaluated according to the non-randomized controlled Newcastle-Ottawa Scale (NOS) [ 11] by two researchers, independently. The inconsistencies were resolved with the help from a third researcher. After assessing the quality of the literature, the data of interest were extracted. The baseline characteristics of the included studies such as the first author, publication time, sex, sample size, detection method, positive expression cutoff value, and sample source were recorded. The primary outcomes were overall survival (OS) and disease-free survival (DFS). The secondary outcomes including the 5-year survival rate and various parameters of esophageal cancer such as Tumor Node Metastasis (TNM) stage, lymph node metastasis, differentiation degree, and invasion were also extracted.

\section{Statistical analysis}

Meta-analysis was performed using RevMan 5.3 software [12]. The heterogeneity between each included study was assessed using the $\chi^{2}$ test. When the results of each study were not statistically heterogeneous $\left(P>0.1, I^{2}<50 \%\right)$, a fixed effects model was used, whereas, in the case of statistical heterogeneity of each study $\left(P<0.1,1^{2}>50 \%\right)$, the source of heterogeneity was analyzed by a subgroup analysis of the preceding factors. When the results of the study were not significantly heterogeneous, the random effects model was applied. The sensitivity analysis was performed to test the heterogeneity of the low-quality studies. Descriptive analysis was used if the data were limited. Begg's and Egger's tests were used to construct the funnel plot, and determine the publication bias.

Calculation and transformation of InHR and its variance: If the included study already provided $\mathrm{HR}$ values and $95 \% \mathrm{Cl}$, the natural logarithm of HR and the $95 \% \mathrm{Cl}$ can be calculated directly; if the HR value was not provided directly, the HR for OS of high STMN1 vs. low STMN1 was calculated from the survival curve as described previously [13,14]. For the 5-year survival rate, the number of surviving patients in each group was calculated. If the combined HR and the $95 \% \mathrm{Cl}$ were $>1$, the high expression of STMN1 was deemed as a risk factor for the prognosis of esophageal cancer. Furthermore, the patients were classified into different groups based on various parameters of esophageal cancer, such as TNM stage, lymph node metastasis, differentiation degree, and invasion. For clinical stages, the patients were grouped into I+II and III+IV groups. For lymph node metastasis and invasion, the yes and no groups were formed. For differentiation degree, the patients were classified into well and intermediate and poor groups. The risk ratio (RR) of high vs.low STMN1 expression in the III+IV, yes, and poor groups was calculated. A difference of $P<0.05$ was considered as statistically significant. 


\section{Results \\ Search results and quality evaluation}

The initial search retrieved a total of 70 articles. The titles and the abstracts were read, and 58 articles including repetitions, animal experiments, and reviews were excluded. Subsequently, the full-texts were analyzed, and four articles that did not meet the inclusion criteria were excluded. Of these, two studies were discarded as they used the data from the same patient population, and the other two studies did not provide sufficient data. Finally, a total of eight studies [ 7, 15-21] retrospective studies were included, which encompassed a total of 1240 patients with esophageal cancer. The study selection process is presented in Fig. 1.

The ethnicity of the subjects in all the included studies was Asian. Among 1240 patients with esophageal cancer, 602 showed a high expression of the STMN1 protein, and 638 had low expression. The clinical stages varied from I to IV across the included studies. The expression of STMN1 was detected by IHC. The baseline characteristics of the included studies are shown in Table 1.

The NOS criteria were employed to assess the quality of the included studies. The quality evaluation demonstrated that the eight studies had distinct diagnostic criteria, sufficient sample size, and data of interest and were ascribed six stars, indicating good quality (Table 2).

\section{STMN1 and prognosis of esophageal cancer patients}

\section{OS}

In order to determine the effect of STMN1 on OS in patients with esophageal cancer, we extracted the HR of high STMN1 vs. low STMN1 from six studies [ 7, 15-17, 19, 21]. As shown in Fig. 2A, no statistically significant heterogeneity was observed between the studies $\left(I^{2}=36 \%\right)$, and a meta-analysis was performed using a fixed-effects model. The results showed that high STMN1 expression had a statistically significant negative effect on OS in patients with esophageal cancer ( $\mathrm{HR}=1.88,95 \% \mathrm{Cl}: 1.61-2.19 ; P<0.00001)$.

\section{DFS}

Next, we examined the correlation between STMN1 expression and DFS in esophageal cancer patients. A total of three articles [ 7, 16 , 17] were included. Any statistical heterogeneity was not detected between the studies $\left(I^{2}=0 \%\right)$, and so the fixed effects model was used. As illustrated in Fig. 2B, the results showed that patients with low STMN1 had a significantly longer DFS than those with high STMN1 (HR=1.59, 95\% Cl: 1.30-1.93; $P<0.00001)$.

\section{5-year survival rate}

Five studies $[7,15,17,19,21]$ reported the 5-year survival rate in patients with different expression levels of STMN1, and slightly significant heterogeneity was detected $\left(I^{2}=56 \%\right)$. Therefore, a random effects model was used for the meta-analysis. A total of 132/443 patients exhibited high STMN1 expression, and 264/428 patients had low STMN1 (Fig. 2C). The results showed that patients with low expression of STMN1 had a significantly higher 5-year survival than those with high STMN1 expression (RR=0.46, $95 \% \mathrm{Cl}: 0.36-0.59 ; P<0.00001)$. To minimize the heterogeneity, we performed sensitivity analysis and found that the $\mathrm{I}^{2}$ decreased to $18 \%$ after excluding the study by Zhu et al., which suggested that this study might be responsible for the significant heterogeneity.

\section{Correlation between STMN1 and clinical parameters of esophageal cancer}

STMN1 and clinical stage

Five studies [ 7, 16, 18-20] reported a number of patients with high vs. low expression of STMN1 in different clinical stages of esophageal cancer, no statistical heterogeneity was noted between the studies $\left(I^{2}=0 \%\right)$. Therefore, a fixed effect model was used. 
The results showed that the risk of III-IV stage disease in patients with high STMN1 expression was 1.62-fold than in those with low STMN1 expression (RR=1.62, 95\% Cl: 1.36-1.92; $P<0.00001)$.

STMN1 and tumor cell differentiation degree

Five studies [ 16, 18-21] reported the correlation between STMN1 and various differentiation grades of esophageal cancer, and statistically significant heterogeneity was detected between the studies $\left(l^{2}=83 \%\right)$. Therefore, a random effects model was used. The results from Fig. 3B showed that low STMN1 expression was in favor of well or intermediate differentiation, albeit without significant difference ( $R R=1.88,95 \% \mathrm{Cl}: 0.86-4.10 ; P=0.11)$. Due to identical sample sources, protein detection method, and disease, it is difficult to conduct a subgroup analysis. Therefore, we performed sensitivity analysis, and the results showed that the study by He et al. introduced a significant heterogeneity (Supplemental Fig. 1).

STMN1 and invasion

Three studies $[7,18,20]$ reported a number of patients with different expression of STMN1 in the positive invasion group, and no statistical heterogeneity was observed between the studies $\left(1^{2}=8 \%\right)$. Therefore, a fixed effects model was applied. The results showed that a 1.75-fold risk of experiencing invasion was found in patients with high STMN1 as compared to those with low expression of STMN1 (RR=1.75, 95\% Cl: $1.43-2.14 ; P<0.00001)$.

STMN1 and lymph node metastasis

Six studies [ 7, 16, 18-21] reported a number of esophageal cancer patients with high vs. low expression of STMN1 with positive lymph node metastasis, and significant heterogeneity was detected between the included studies $\left(I^{2}=87 \%\right)$; thus, the random effects model was applied. As shown in Fig. 3D, the combined result showed that patients with high STMN1 expression had a significantly high risk of developing lymph node metastasis than those with low STMN1 expression (RR=2.33, 95\% Cl: 1.44-3.77; $P=0.0006$ ). Because of significant heterogeneity, we performed a sensitivity analysis to determine the responsible study. As illustrated in Supplemental Fig. 2, the study of Suzuki et al. might be the main source of differences.

\section{Publication bias analysis}

A funnel plot was used to detect the publication bias based on the data of OS and 5-year survival. The included studies were presented on the respective plots and spread out with the combined values as the center. The distribution and symmetry of the plots suggested the absence of significant publication bias (Fig. 4). Furthermore, Begg's and Egger's tests did not show any significant publication bias (Begg's Test: $P=0.806$ for OS, $P=0.221$ for 5 -year survival; Egger's test: $P=1.0$ for 0 , $P=0.105$ for 5 -year survival).

\section{Discussion}

In this study, we performed a systematic review and comprehensive search to identify clinical studies that fulfilled the inclusion criteria. These retrospective studies had determined the potential correlation between STMN1 expression and the prognosis of patients with esophageal carcinoma, as well as clinical stage, lymphatic metastasis, tissue differentiation, and invasion. Finally, eight studies comprising of a total of 1240 cases were included for quantitative analysis. The results of the meta-analysis showed that the high expression of STMN1 was an indicator of poor OS and DFS in patients with esophageal cancer. High STMN1 expression was associated with an increased risk of poor clinical stage, invasion, lymph node metastasis, and poor tissue differentiation grades, suggesting that STMN1 might be a potential biomarker for esophageal cancer patients after surgery.

The poor prognosis of esophageal cancer is often associated with invasiveness and metastasis [1, 11]. Therefore, the physiological indicators related to the development and prognosis of esophageal cancer are required. In recent years, STMN1 has been reported to play a key role in the prognosis of esophageal cancer, suggesting that it is a cancer-associated gene [ 5, 9, 22, 23]. In the present meta-analysis, six studies compared the OS of esophageal cancer patients with high vs. low expression of STMN1, and the results suggested that high STMN1 was associated with poor OS. Therefore, it can be speculated that high STMN1 expression might play a vital role in predicting the outcome of esophageal cancer. Subsequently, we found that high expression of STMN1 was involved in advanced stage, lymphatic metastasis, and invasion.

Page 5/13 
Moreover, two meta-analyses [ 5, 22] aimed to evaluate the role of STMN1 in various cancers. In 2016, the meta-analysis by Rong et al. [ 5] disclosed the STMN1 expression patterns in several cancers and clarified the connection between STMN1 and malignant diseases. After including 25 studies with 3571 individuals, the study found that cancer patients displayed a higher STMN1 expression than those without cancers (odds ratio $(\mathrm{OR})=0.31$ ), and high STMN1 correlated with tumor cell differentiation $(\mathrm{OR}=0.73)$, lymph node metastasis $(\mathrm{OR}=0.80)$ and poor clinical stage $(\mathrm{OR}=0.67)$. Finally, the study concluded that cancer patients with high STMN1 expression had a shorter survival duration (27.93 \pm 11.54 months) as compared to those with moderate and low STMN1 expression (44.81 \pm 15.82 months) [ 5]. Another meta-analysis performed by Mao et al. [22] assessed the prognostic value of STMN1 in patients with solid cancers. The study included 26 studies involving 5335 patients, and the results showed that high STMN1 yielded a poor OS $(H R=2.17)$, and DFS $(H R=2.46)$. These findings were in accordance with the results of the current study. Both studies suggested a negative correlation between the expression of STMN1 and survival of various cancer patients. However, the specific link between STMN1 and prognosis of esophageal cancer is not elucidated in these studies. Herein, we provided additional evidence about the prognostic role of STMN1 in esophageal cancer patients.

Nevertheless, the present study has some limitations. First, although we conducted a relatively comprehensive search, the lack of gray literature might lead to publication bias. All the included studies were conducted in Asia, which might restrict the reliability. Second, the quality of the retrospective studies was moderate. Some of the included studies might have a selection bias. Two studies did not provide survival data and might introduce selective reporting bias. Third, the number of retrieved studies was small with a limited number of patients. Four, heterogeneities were detected in terms of baseline characteristics, tumor differentiation, and clinical staging, as well as the definition of high or low STMN1. In order to decrease the impact of these differences on the pooled outcomes, the random effects model was used for improved credibility. In addition, the sensitivity analysis was performed to explore the source of heterogeneity.

\section{CONCLUSION}

In summary, the expression of STMN1 in esophageal cancer is a prognostic factor for survival. The high STMN1 expression is associated with poor clinical stage, positive lymph node metastasis, and poor histological grades, indicating that STMN1 may play a critical role in the development and progression of esophageal carcinoma. However, additional rigorous, meticulous, high-quality studies are essential to substantiate these findings.

\section{List Of Abbreviation}

Chinese Biomedical Literature Database (CBM), overall survival (OS), disease-free survival (DFS), immunohistochemistry (IHC), hazard ratio (HR), confidence interval (Cl), Newcastle-Ottawa Scale (NOS), Tumor Node Metastasis (TNM).

\section{Declaration}

\section{Ethics approval and consent to participate}

This is a meta-analysis of data from published articles, it is necessary ethical approval

\section{Consent for publication}

Not applicable.

\section{Availability of data and material}

The datasets used and/or analyzed during the current study are available from the corresponding author on reasonable request.

\section{Competing interests}




\section{All authors declare that they have no any conflict of interests.}

\section{Funding}

The study Supported by the National Natural Science Fund of China.

\section{Authors' contributions}

Shasha Cao and Wei Zhang carried out the studies, participated in collecting data, and drafted the manuscript. Shasha Cao and Peihong Shen performed the statistical analysis and participated in its design. Shasha Cao and Ruiping Xu participated in acquisition, analysis, or interpretation of data and draft the manuscript. All authors read and approved the final manuscript.

\section{Acknowledgement}

None.

\section{References}

1. Li YY, Du LB, Hu XQ, Jaiswal S, Gu SY, Gu YX, et al. A Suggested Framework for Conducting Esophageal Cancer Screening in China. J Dig Dis. 2018.

2. Wang J, Sun D, Wu K, Liu J, Zhao M, Li X, et al. Genome-wide analysis of long non-coding RNAs in esophageal squamous cell carcinoma reveals their potential role in invasion and metastasis. Thorac Cancer. 2018.

3. Honnappa S, Jahnke W, Seelig J, Steinmetz MO. Control of intrinsically disordered stathmin by multisite phosphorylation. J Biol Chem. 2006;281(23):16078-16083.

4. Kuang XY, Chen L, Zhang ZJ, Liu YR, Zheng YZ, Ling H, et al. Stathmin and phospho-stathmin protein signature is associated with survival outcomes of breast cancer patients. Oncotarget. 2015;6(26):22227-22238.

5. Biaoxue R, Hua L, Wenlong G, Shuanying Y. Overexpression of stathmin promotes metastasis and growth of malignant solid tumors: a systemic review and meta-analysis. Oncotarget. 2016;7(48):78994-79007.

6. Kim JY, Harvard C, You L, Xu Z, Kuchenbecker K, Baehner R, et al. Stathmin is overexpressed in malignant mesothelioma. Anticancer Res. 2007;27(1A):39-44.

7. Suzuki S, Yokobori T, Altan B, Hara K, Ozawa D, Tanaka N, et al. High stathmin 1 expression is associated with poor prognosis and chemoradiation resistance in esophageal squamous cell carcinoma. Int J Oncol. 2017.

8. Ni PZ, He JZ, Wu ZY, Ji X, Chen LQ, Xu XE, et al. Overexpression of Stathmin 1 correlates with poor prognosis and promotes cell migration and proliferation in oesophageal squamous cell carcinoma. Oncology Reports. 2017;38(6):3608-3618.

9. Wu J, Li S, Ma R, Sharma A, Bai S, Dun B, et al. Tumor profiling of co-regulated receptor tyrosine kinase and chemoresistant genes reveal different targeting options for lung and gastroesophageal cancers. American Journal of Translational Research.

2016;8(12):5729-5740.

10. Liu F, Liu F, Sun YL, Zhao XH. Significance of STMN1 expression in esophageal squamous cell carcinoma. World Chinese Journal of Digestology. 2010;18(13):1306-1312.

11. Stang A. Critical evaluation of the Newcastle-Ottawa scale for the assessment of the quality of nonrandomized studies in metaanalyses. European journal of epidemiology. 2010;25(9):603-605.

12. Green S, Higgins J. Cochrane handbook for systematic reviews of interventions. Version; 2005. 
13. Parmar MK, Torri V, Stewart L. Extracting summary statistics to perform meta-analyses of the published literature for survival endpoints. Stat Med. 1998;17(24):2815-2834.

14. Williamson PR, Smith CT, Hutton JL, Marson AG. Aggregate data meta-analysis with time-to-event outcomes. Stat Med. 2002;21(22):3337-3351.

15. Akhtar J, Wang Z, Yu C, Zhang ZP, Bi MM. STMN-1 gene: a predictor of survival in stage iia esophageal squamous cell carcinoma after Ivor-Lewis esophagectomy? Ann Surg Oncol. 2014;21(1):315-321.

16. He JZ, Wu ZY, Wang SH, Ji X, Yang CX, Xu XE, et al. A decision tree-based combination of ezrin-interacting proteins to estimate the prognostic risk of patients with esophageal squamous cell carcinoma. Hum Pathol. 2017;66:115-125.

17. Ni PZ, He JZ, Wu ZY, Ji X, Chen LQ, Xu XE, et al. Overexpression of Stathmin 1 correlates with poor prognosis and promotes cell migration and proliferation in oesophageal squamous cell carcinoma. Oncol Rep. 2017;38(6):3608-3618.

18. Wang F, Wang LX, He W, Zhu LN, Zhao PR, Fan QX. Expression of stathmin in esophageal squamous cell carcinoma and its biological significance. Nan Fang Yi Ke Da Xue Xue Bao. 2010;30(7):1552-1557.

19. Wang F, Xuan XY, Yang X, Cao L, Pang LN, Zhou R, et al. Stathmin is a marker of progression and poor prognosis in esophageal carcinoma. Asian Pac J Cancer Prev. 2014;15(8):3613-3618.

20. Xiao; W, Qingxia; F, Peirong; Z, Feng W. Expression and Significance of Stathmin in Esophageal Squamous Cell Carcinoma. JOURNAL OF BASIC AND CLINICAL ONCOLOGY. 2007 (5):372-374.

21. Hongwu; Z, Dan; Ji, Ziying; X, Qiaoxun; M, Changxian; L, Meihua; Z, et al. Role of STMN1 in esophageal squamous cell carcinoma invasion and metastasis and its prognostic significance in human patients. Chongqing Medicine. 2015 (7):865-868,872.

22. Mao Q, Chen Z, Wang K, Xu R, Lu H, He X. Prognostic Role of High Stathmin 1 Expression in Patients with Solid Tumors: Evidence from a Meta-Analysis. Cell Physiol Biochem. 2018;50(1):66-78.

23. Jiang W, Huang S, Song L, Wang Z. STMN1, a prognostic predictor of esophageal squamous cell carcinoma, is a marker of the activation of the PI3K pathway. Oncol Rep. 2018;39(2):834-842.

\section{Tables}

Table 1 Baseline characteristics of included studies 


\begin{tabular}{|c|c|c|c|c|c|c|c|c|c|c|c|c|}
\hline \multirow[t]{2}{*}{ Author } & \multirow[t]{2}{*}{ Year } & \multirow[t]{2}{*}{ Design } & \multicolumn{2}{|c|}{ STMN1 } & \multirow[t]{2}{*}{ Region } & \multirow{2}{*}{$\begin{array}{c}\text { Mean } \\
\text { Age }\end{array}$} & \multirow{2}{*}{$\begin{array}{l}\text { Sex, } \\
\text { male }\end{array}$} & \multirow[t]{2}{*}{ Stage } & \multirow{2}{*}{$\begin{array}{l}\text { Cutoff } \\
\text { value }\end{array}$} & \multirow[t]{2}{*}{ Detection } & \multirow{2}{*}{$\begin{array}{l}\text { Sample } \\
\text { source }\end{array}$} & \multirow[t]{2}{*}{ Outcomes } \\
\hline & & & high & low & & & & & & & & \\
\hline Akhtar & 2013 & Retrospective & 94 & 68 & Asia & 59.8 & 126 & IIA & $\begin{array}{c}\text { IHC } \\
\text { score } \\
\geq 4\end{array}$ & IHC & $\begin{array}{c}\text { Formalin- } \\
\text { fixed and } \\
\text { paraffin- } \\
\text { embedded } \\
\text { sections }\end{array}$ & $\begin{array}{l}\text { 5-year } \\
\text { SR, OS }\end{array}$ \\
\hline $\mathrm{He}$ & 2017 & Retrospective & 91 & 172 & Asia & 58 & 209 & I-III & $\begin{array}{l}\text { mean } \\
\text { score }\end{array}$ & IHC & $\begin{array}{l}\text { Formalin- } \\
\text { fixed and } \\
\text { paraffin- } \\
\text { embedded } \\
\text { sections }\end{array}$ & $\begin{array}{l}\text { OS, DFS, } \\
\text { prognosis }\end{array}$ \\
\hline $\mathrm{Ni}$ & 2017 & Retrospective & 94 & 193 & Asia & 55 & 218 & I-III & $\begin{array}{l}\text { mean } \\
\text { score }\end{array}$ & IHC & $\begin{array}{c}\text { Formalin- } \\
\text { fixed and } \\
\text { paraffin- } \\
\text { embedded } \\
\text { sections }\end{array}$ & $\begin{array}{c}\text { 5-year } \\
\text { SR, OS, } \\
\text { DFS }\end{array}$ \\
\hline Wang & 2010 & Retrospective & 51 & 24 & Asia & 60.5 & 45 & I-IV & $\begin{array}{l}\text { IHC } \\
\text { score } \\
\geq 4\end{array}$ & IHC & $\begin{array}{l}\text { Formalin- } \\
\text { fixed and } \\
\text { paraffin- } \\
\text { embedded } \\
\text { sections }\end{array}$ & prognosis \\
\hline Suzuki & 2017 & Retrospective & 97 & 75 & Asia & 63.4 & 158 & I-IV & $\begin{array}{l}\text { mean } \\
\text { score }\end{array}$ & IHC & $\begin{array}{l}\text { Formalin- } \\
\text { fixed and } \\
\text { paraffin- } \\
\text { embedded } \\
\text { sections }\end{array}$ & $\begin{array}{c}\text { 5-year } \\
\text { SR, OS, } \\
\text { DFS, } \\
\text { prognosis }\end{array}$ \\
\hline Wang & 2014 & Retrospective & 57 & 43 & Asia & 64 & 68 & I-IV & $\begin{array}{c}\text { IHC } \\
\text { score }>3\end{array}$ & IHC & $\begin{array}{l}\text { Formalin- } \\
\text { fixed and } \\
\text { paraffin- } \\
\text { embedded } \\
\text { sections }\end{array}$ & $\begin{array}{c}\text { 5-year } \\
\text { SR, OS, } \\
\text { prognosis }\end{array}$ \\
\hline Wang & 2007 & Retrospective & 17 & 14 & Asia & 60 & 16 & I-IV & $\begin{array}{l}\text { mean } \\
\text { score }\end{array}$ & IHC & $\begin{array}{l}\text { Formalin- } \\
\text { fixed and } \\
\text { paraffin- } \\
\text { embedded } \\
\text { sections }\end{array}$ & prognosis \\
\hline Zhu & 2015 & Retrospective & 101 & 49 & Asia & 64 & 113 & I-III & $\begin{array}{l}\text { mean } \\
\text { score }\end{array}$ & IHC & $\begin{array}{c}\text { Formalin- } \\
\text { fixed and } \\
\text { paraffin- } \\
\text { embedded } \\
\text { sections }\end{array}$ & $\begin{array}{c}\text { 5-year } \\
\text { SR, OS, } \\
\text { prognosis }\end{array}$ \\
\hline
\end{tabular}

Abbreviation: STMN1, stathmin 1; IHC, Immunohistochemistry; SR, survival rate; OS, overall survival; DFS, disease free survival;

Table 2 Quality assessment of included studies by NOS

\begin{tabular}{|c|c|c|c|c|}
\hline Author & Year & Selection & Comparability & Outcome \\
\hline Akhtar & 2013 & प्राप & पा & पा \\
\hline $\mathrm{He}$ & 2017 & 0 & 0 & प्रा \\
\hline $\mathrm{Ni}$ & 2017 & ०स & $\mathrm{QP}$ & प्या \\
\hline Wang & 2010 & प्रा & 吅 & प्रा \\
\hline Suzuki & 2017 & 䏝 & 0 & प्स \\
\hline Wang & 2014 & प्स & 0 & प्सा \\
\hline Wang & 2007 & 吅 & $\mathrm{Qu}$ & 吅 \\
\hline Zhu & 2015 & 吅 & $\mathrm{Qu}$ & 吅 \\
\hline
\end{tabular}




\section{Additional File Legend}

Supplemental Figure 1 Sensitivity analysis based on the expression of STMN1 and degree of tumor cell differentiation.

Supplemental Figure 2 Sensitivity analysis with respect to the analysis of STMN1 and lymph node metastasis.

\section{Figures}
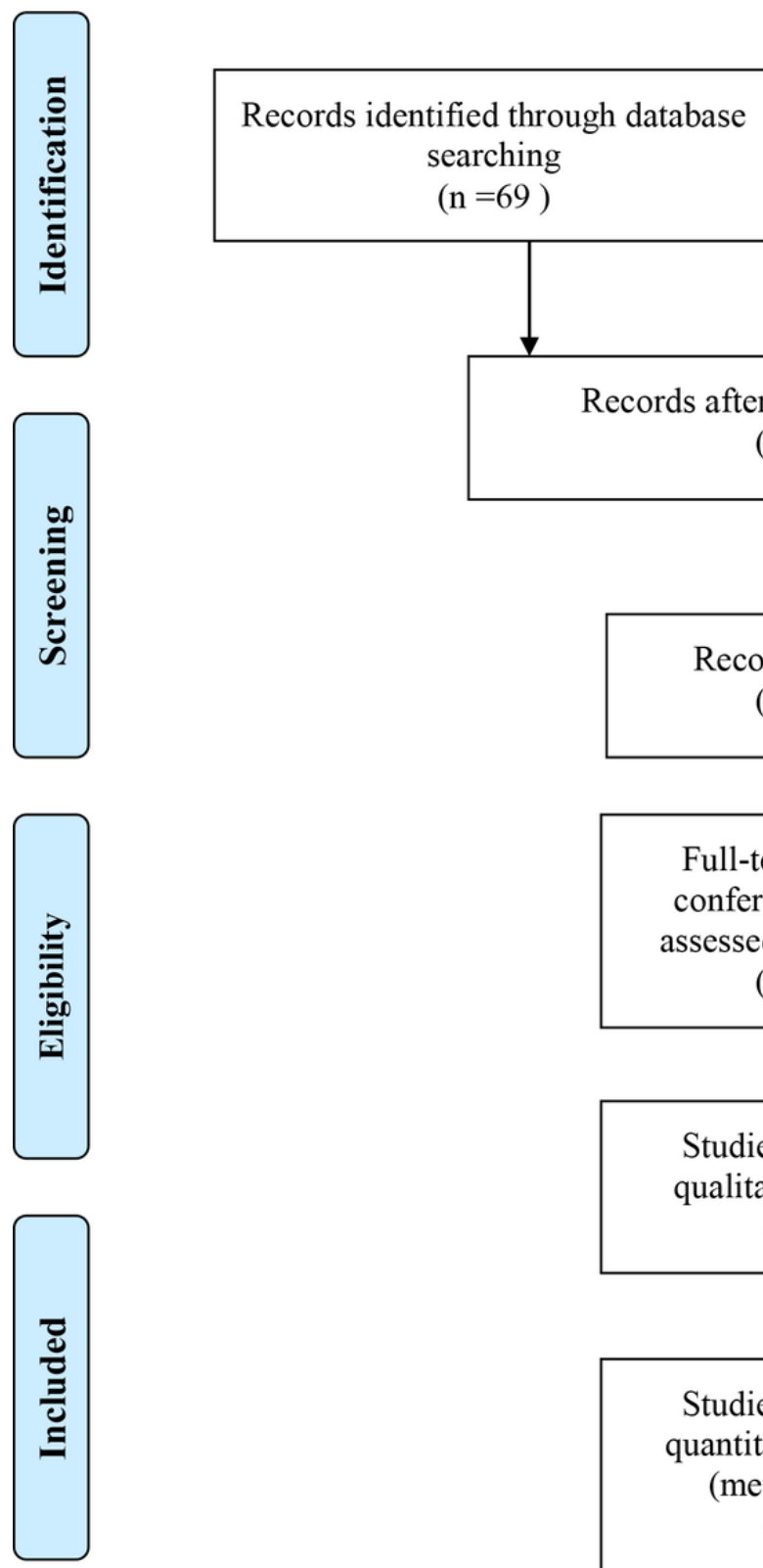

$$
(\mathrm{n}=69)
$$

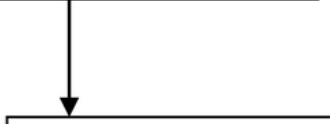

Records after duplicates removed

$$
(\mathrm{n}=62)
$$

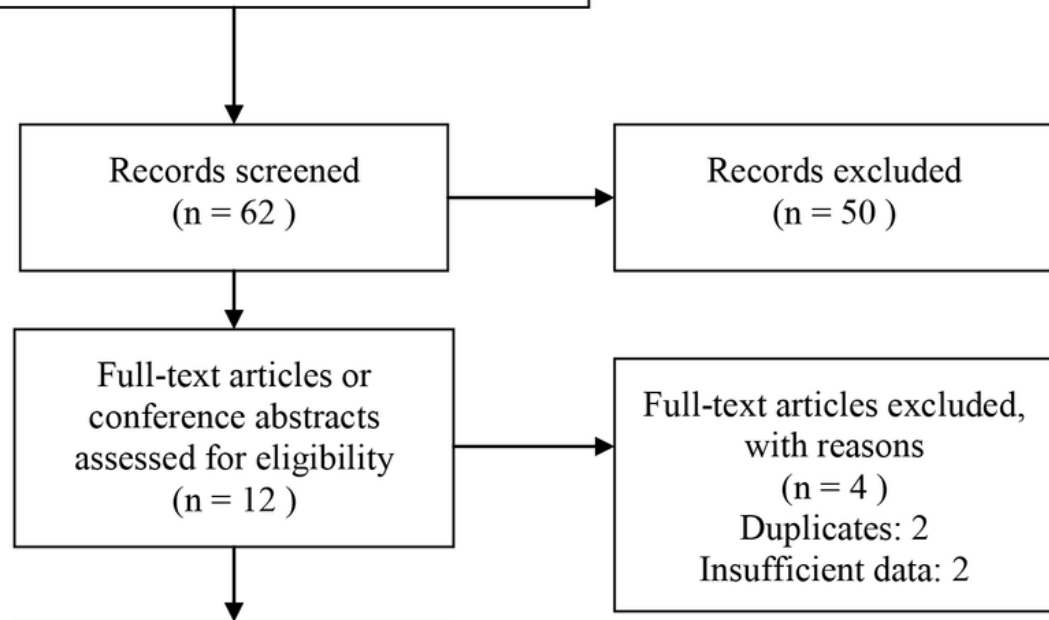

Studies included in qualitative synthesis

$$
(\mathrm{n}=8)
$$

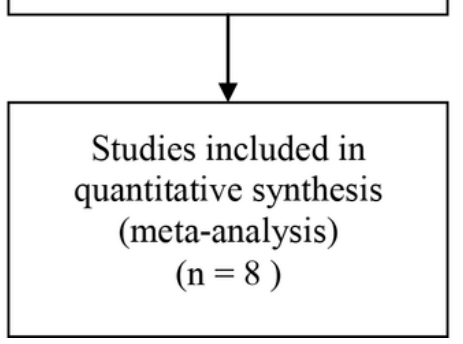

Additional records identified through other sources $(\mathrm{n}=1)$

\section{Figure 1}

Schematic of the selection of eligible studies 
A

Hazard Ratio

Study or Subgroup log[Hazard Ratio] SE Weight IV. Fixed. 95\% Cl

Akhtar 2014

He 2017

Ni 2017

Suzuki 2017

Wang 2014

Zhu 2015

Total $(95 \% \mathrm{Cl})$

Heterogeneity: $\mathrm{Chi}^{2}=7.80, \mathrm{df}=5(\mathrm{P}=0.17) ; \mathrm{I}^{2}=36 \%$

Test for overall effect: $Z=8.06(P<0.00001)$

B

\begin{tabular}{lrrrr} 
Study or Subgroup & log[Hazard Ratio] & SE & Weight & IV. Fixed. 95\% Cl \\
\hline He 2017 & 0.4187 & 0.1664 & $36.4 \%$ & $1.52[1.10,2.11]$ \\
Ni 2017 & 0.5693 & 0.1653 & $36.8 \%$ & $1.77[1.28,2.44]$ \\
Suzuki 2017 & 0.3716 & 0.1938 & $26.8 \%$ & $1.45[0.99,2.12]$ \\
& & & $100.0 \%$ & $1.59[1.30,1.93]$
\end{tabular}

Heterogeneity: $\mathrm{Chi}^{2}=0.71, \mathrm{df}=2(\mathrm{P}=0.70) ; \mathrm{I}^{2}=0 \%$

Test for overall effect: $Z=4.60(P<0.00001)$

C Study or Subgroup $\begin{array}{lll}\text { High STMN1 Low STMN1 } \\ \text { Events Total Events Tot }\end{array}$

$\begin{array}{lrrrrr}\text { Akhtar 2014 } & 27 & 94 & 41 & 68 & 19.8 \% \\ \text { Ni } 2017 & 20 & 94 & 104 & 193 & 18.0 \% \\ \text { Suzuki 2017 } & 42 & 97 & 53 & 75 & 25.2 \% \\ \text { Wang 2014 } & 21 & 57 & 31 & 43 & 19.0 \% \\ \text { Zhu 2015 } & 22 & 101 & 35 & 49 & 18.0 \% \\ & & & & & \\ \text { Total (95\% Cl) } & & 443 & & 428 & 100.0 \% \\ \text { Total events } & 132 & & 264 & & \end{array}$

Heterogeneity: $\mathrm{Tau}^{2}=0.04 ; \mathrm{Chi}^{2}=9.04, \mathrm{df}=4(\mathrm{P}=0.06) ; I^{2}=56 \%$

Test for overall effect: $Z=6.23(P<0.00001)$
Hazard Ratio

IV. Fixed. $95 \% \mathrm{Cl}$

$25.1 \% \quad 1.90[1.40,2.58]$

$21.6 \% \quad 1.41[1.02,1.97]$

$22.4 \% \quad 2.15[1.55,2.97]$

$18.4 \% \quad 1.80[1.26,2.57]$

$7.7 \% \quad 1.87[1.08,3.24]$

$4.9 \% \quad 3.89[1.94,7.78]$

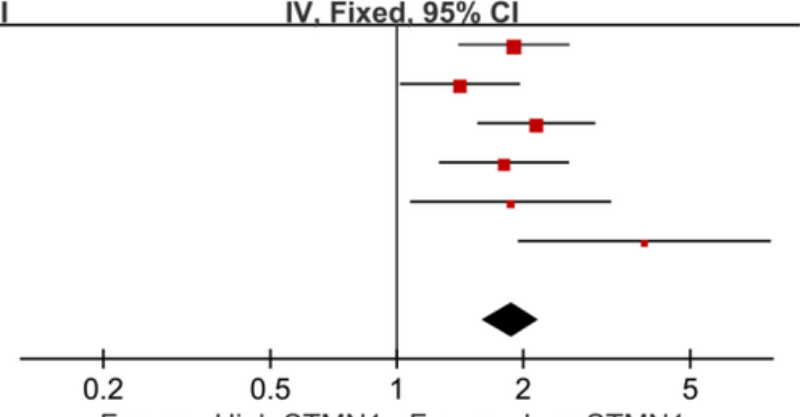

Favours High STMN1 Favours Low STMN1

Hazard Ratio IV. Fixed. $95 \% \mathrm{Cl}$

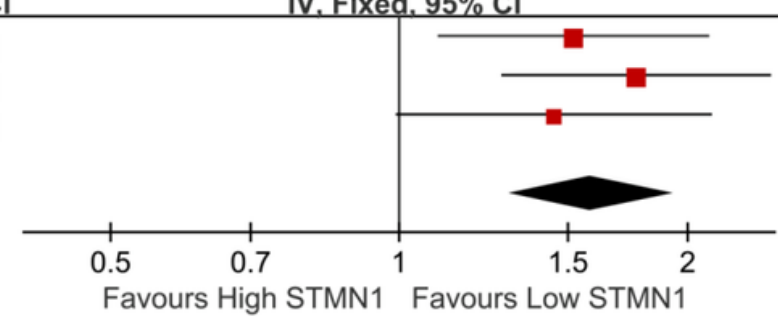

Favours High STMN1 Favours Low STMN1

Risk Ratio

Risk Ratio

Random, $95 \%$ C

$0.48[0.33,0.69]$

$0.39[0.26,0.60]$

$0.61[0.47,0.80]$

$0.51[0.35,0.75]$

$0.30[0.20,0.46]$

$0.46[0.36,0.59]$

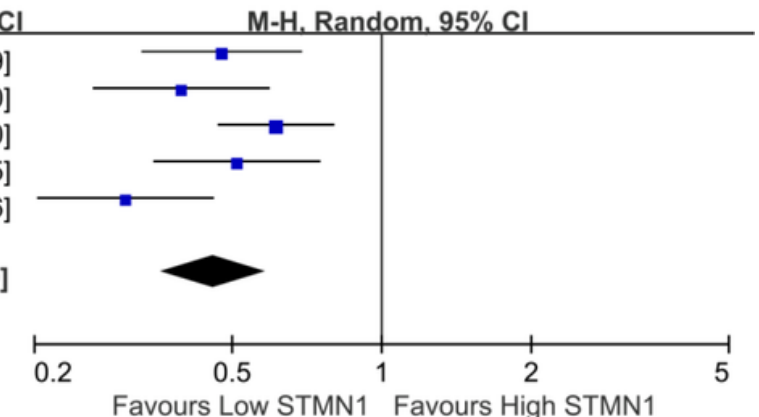

Figure 2

Meta-analysis of the effects of high vs. low STMN1 on OS, DFS, and 5-year survival rate in patients with esophageal cancer. A, OS; B, DFS; C, 5-year survival rate. 


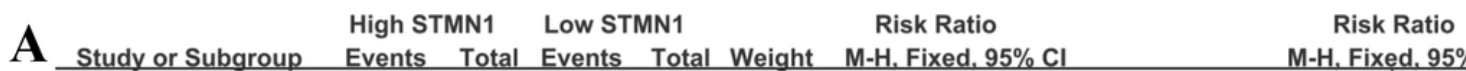

$\begin{array}{lrrrrrr}\text { He } 2017 & 56 & 91 & 62 & 172 & 39.1 \% & 1.71[1.32,2.21] \\ \text { Suzuki 2017 } & 51 & 97 & 26 & 75 & 26.8 \% & 1.52[1.05,2.18] \\ \text { Wang 2007 } & 7 & 13 & 5 & 18 & 3.8 \% & 1.94[0.79,4.76] \\ \text { Wang 2010 } & 36 & 49 & 12 & 26 & 14.3 \% & 1.59[1.02,2.49] \\ \text { Wang 2014 } & 49 & 73 & 12 & 27 & 16.0 \% & 1.51[0.96,2.37] \\ & & & & & & \\ \text { Total (95\% Cl) } & & 323 & & 318 & 100.0 \% & 1.62[1.36,1.92] \\ \text { Total events } & 199 & & 117 & & & \end{array}$

Heterogeneity: $\mathrm{Chi}^{2}=0.54, \mathrm{df}=4(\mathrm{P}=0.97) ; \mathrm{I}^{2}=0 \%$

Test for overall effect: $Z=5.45(P<0.00001)$

B High STMN1 Low STMN1

Study or Subgroup Events Total Events Total Weight $\mathrm{M}-\mathrm{H}$. Random. 95\% Cl

$\begin{array}{lllllll}\text { He } 2017 & 81 & 91 & 143 & 172 & 27.8 \% & 1.07[0.97,1.18]\end{array}$

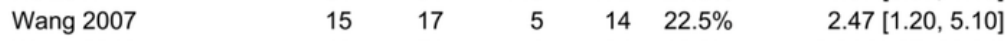

$\begin{array}{lllllll}\text { Wang } 2010 & 19 & 51 & 1 & 24 & 10.2 \% & 8.94[1.27,62.94]\end{array}$

$\begin{array}{lllllll}\text { Wang } 2014 & 26 & 73 & 3 & 27 & 17.8 \% & 3.21[1.06,9.73]\end{array}$

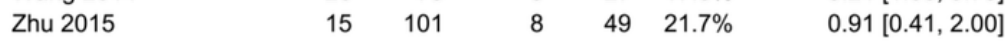

$\begin{array}{lllll}\text { Total }(95 \% \mathrm{Cl}) & 333 & 286 & 100.0 \% & 1.88[0.86,4.10]\end{array}$

$\begin{array}{lcc}\text { Total events } & 156 & 160 \\ \text { Heterogeneity: } \mathrm{Tau}^{2}=0.57 \cdot \mathrm{Ch}^{2}=23.46, \mathrm{df}=4(\mathrm{P}=0.0001): \mathrm{I}^{2}=83 \%\end{array}$

Test for overall effect: $Z=1.59(P=0.11)$

\begin{tabular}{lllll} 
& \multicolumn{2}{c}{ High STMN1 Low STMN1 } & Risk Ratio \\
C Study or Subgroup Events Total Events Total Weight & M-H. Fixed, 95
\end{tabular} $\begin{array}{lrrrrrr}\text { Suzuki } 2017 & 83 & 97 & 41 & 75 & 71.6 \% & 1.57[1.25,1.95]\end{array}$ $\begin{array}{lllllll}\text { Wang } 2007 & 15 & 17 & 6 & 14 & 10.2 \% & 2.06[1.10,3.86]\end{array}$

Wang 2010

$\begin{array}{llllll}39 & 49 & 9 & 26 & 18.2 \% & 2.30[1.33,3.97]\end{array}$

Total $(95 \% \mathrm{Cl})$

163

Total events $137 \quad 56$

Heterogeneity: $\mathrm{Chi}^{2}=2.18, \mathrm{df}=2(\mathrm{P}=0.34) ; \mathrm{I}^{2}=8 \%$

Test for overall effect: $Z=5.45(P<0.00001)$

$\begin{array}{lllll}\text { D High STMN1 } & \text { Low STMN1 } & \text { Risk Ratio } \\ \text { Study or Subgroup } & \text { Events Total Events Total Weight } & \text { M-H. Random, 95\% Cl }\end{array}$

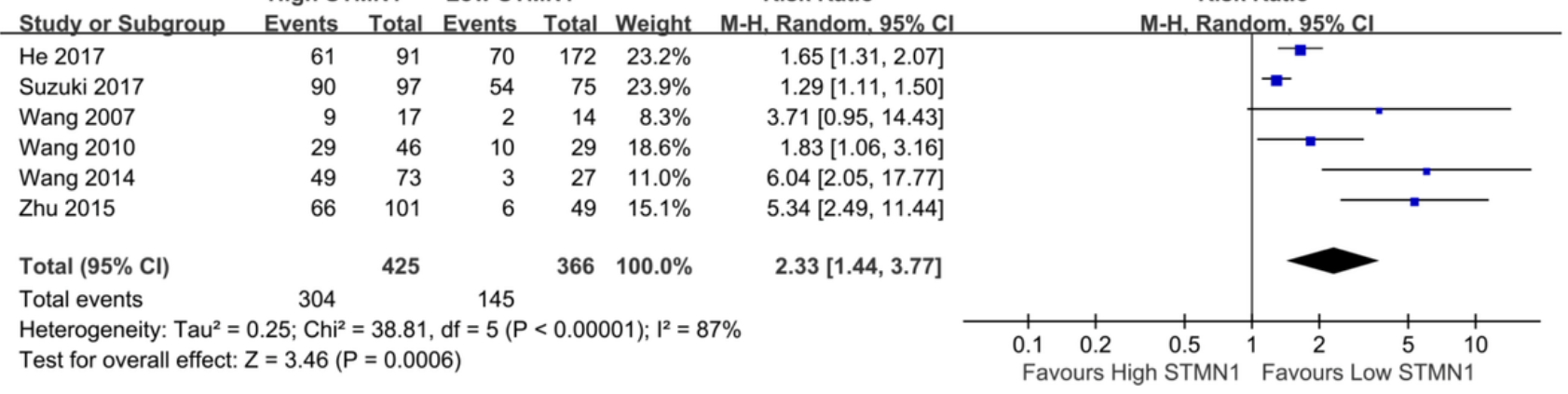

Figure 3

Meta-analysis to evaluate the correlation between the expression of STMN1 and clinical parameters. A, Correlation between poor clinical stage and STMN1; B, Correlation between poor differentiation and STMN1; C, Correlation between tumor invasion and STMN1; D, Correlation between lymph node metastasis and STMN1. 

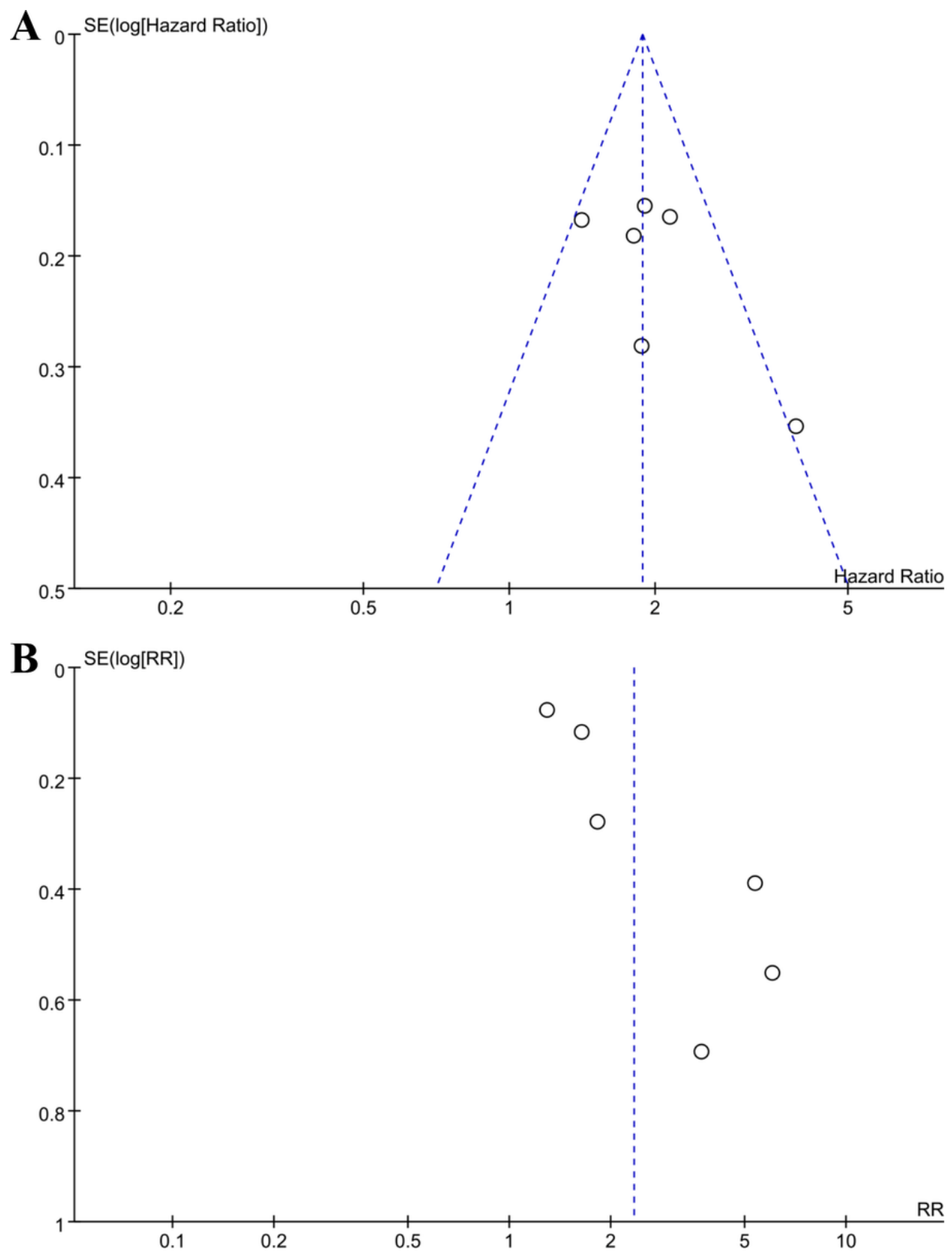

Figure 4

Funnel plot to detect the publication bias. A, Funnel plot of OS; B, Funnel plot of 5-year survival rate

\section{Supplementary Files}

This is a list of supplementary files associated with this preprint. Click to download.

- SupplementalFigure2.tif

- SupplementalFigure1.tif 